\title{
CrimRxiv
}

\section{Colonial Systems of Control: Criminal Justice in Nigeria}

Viviane Saleh-Hanna

Published on: Jul 01, 2018

DOI: 10.21428/cb6ab371.f03f18b3

License: Creative Commons Attribution 4.0 International License (CC-BY 4.0). 
